\title{
Neglected Pessary Perforating Small Bowel: A Case Report
}

Thuraya Al-Badr ${ }^{1}$, Lubna Al-Badr ${ }^{1}$ and Ahmed Al-Badr ${ }^{2 *}$

${ }^{1}$ College of Medicine, AlFaisal University, Riyadh, Kingdom of Saudi Arabia

${ }^{2}$ Department of Urogynecology and Pelvic Reconstructive Surgery, Women's Specialized Hospital, King Fahad Medical City, Riyadh, Kingdom of Saudi Arabia

\begin{abstract}
Pessaries are commonly used to treat pelvic organ prolapse. Although the success rate is usually high, complications may arise if neglected for a long time. There is a general lack of literature regarding pessary use, and specifically related to pessary complications. This is the first case report of a pessary-related complication in Saudi Arabia, as well as the first report of a pessary perforating the small bowel. In our patient, the pessary had been neglected for 20 years, leading to the perforation of the small bladder and the formation of a fistula. Pessary was successfully removed and fistula corrected. Recommendations to avoid such complications include maintenance of pessary and routine follow-up with a physician. Although such complications have been declining in recent years due to increased awareness, it is important that practitioners are reminded that complications still may occur.
\end{abstract}

\section{Introduction}

Pessaries are commonly indicated as conservative management for women with pelvic organ prolapse (POP). They are also useful in relieving symptoms of patients with surgery contraindications, as well as preventing the progress of existing POP $[1,2]$.

In fact, it has been estimated that $77 \%$ of women in the United States with POP use pessaries [3]. However, data regarding Saudi women use of pessaries is limited, although it is common in practice.

Pessaries should be routinely removed and cleaned, either daily to weekly by the patient, or every 2-3 months in the clinic. Follow-ups are also necessary to examine the vagina for erosions, bruises and the formation of granulation tissue [3].

Complications due to pessaries are generally rare, and mostly attributed to lack of maintenance and leaving them neglected for years. There have been many reports of neglected pessaries causing complications ranging from foul smelling discharge, to fistulas, to hydronephrosis and sepsis [4-8].

Prevalence of POP and use of pessary in Saudi Arabia (SA) is not documented. Nevertheless, the prevalence of urinary incontinence (UI) in SA [9] seems to be higher than international figures [10]. Moreover, as POP is the presenting complaint of $47.7 \%$ of women presenting to the urogynecology clinic at a tertiary care hospital [11], we expect POP to be more prevalent in the country. Therefore, more patients are possibly exposed to pessary use and complication if not cared for properly.

To the extent of our knowledge, this is the first and only case report of a pessary complication in SA, as well as the only report of a pessary causing perforation of the small bowel.

\section{Case}

A 77-year-old bedridden woman presented with a chief complaint of the passage of stool from the vagina for the past 3 years. She is nulliparous and postmenopausal for 30 years. Her surgical history is unremarkable. She had a cerebrovascular accident 20 years ago, and cannot walk nor communicate. Her pessary was inserted 20 years ago for prolapse, and she has had a Foley's catheter inserted for the past 4 months because of UI.
On physical examination, there was an excoriation of the vulvar skin, foreign body in the vagina, and soft stool per vagina. It was difficult to perform a proper examination due to pain. The assessment was a possible rectovaginal fistula, with the foreign body possibly being a retained pessary.

After clearance by internal medicine, examination under general anesthesia was performed. On examination, she had bedsores on both her buttocks and back. Skin erythema in the entire perineum made it difficult to perform a proper pelvic examination. The stool was leaking through the vagina. A hard silicone ring pessary was found high up in the vagina with greenish discharge (Figure 1). There was a

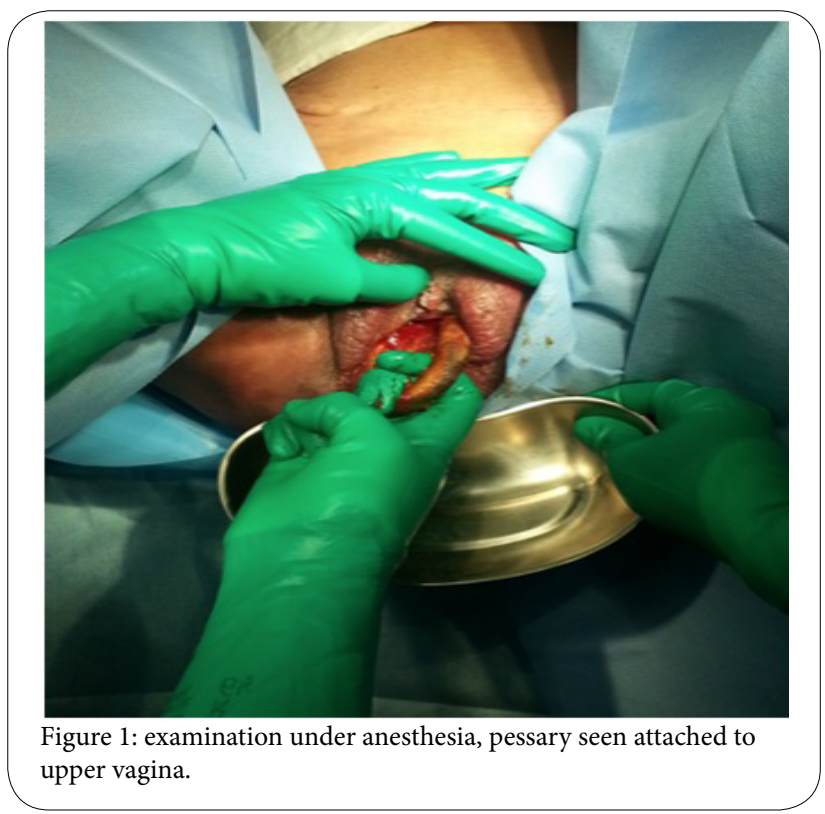

"Corresponding Author: Dr. Ahmed Al-Badr, Department of Urogynecology and Pelvic Reconstructive Surgery, Women's Specialized Hospital, King Fahad Medical City, Riyadh, Kingdom of Saudi Arabia; E-mail: aalbadr@kfmc.med.sa

Citation: Al-Badr T, Al-Badr L, Al-Badr A (2016) Neglected Pessary Perforating Small Bowel: A Case Report. Int J Gynecol Clin Pract 3: 122. doi: http://dx.doi. org/10.15344/2394-4986/2016/122

Copyright: (c) $2016 \mathrm{Al}-\mathrm{Badr}$ et al. This is an open-access article distributed under the terms of the Creative Commons Attribution License, which permits unrestricted use, distribution, and reproduction in any medium, provided the original author and source are credited. 
Citation: Al-Badr T, Al-Badr L, Al-Badr A (2016) Neglected Pessary Perforating Small Bowel: A Case Report. Int J Gynecol Clin Pract 3: 122. doi: http://dx.doi. org/10.15344/2394-4986/2016/122

Page 2 of 2

large band of tissue surrounding the upper part of the pessary, which was dividing to release the pessary. After the pessary was removed, vaginal examination showed part of the small intestine opening into the upper anterior part of the vagina. Rectal examination showed no rectovaginal track.

A general surgeon was consulted, who confirmed small bowel opening. Laparoscopy was performed, and pessary seemed to perforate through the small bowel. Small bowel re-anastomosis was performed by laparoscopy. She recovered well postoperatively, and was discharged several days later.

Eleven months later, she presented for follow-up. There was no passage of stool through the vagina but there was a complaint of continuous leakage of urine. Due to her weakness and her relatives' inability to carry her, diapers were used for urination. On physical exam, there was no prolapse nor discharge, but vagina was scarred. Patient's caregiver consent was obtained prior to writing the report.

\section{Discussion}

Prolapse, a protrusion of the vaginal wall which results from the descent of the female pelvic organs, is a widespread condition among women, especially those of old age. Pregnancy, childbirth, obesity, increased abdominal strain, and increase in age are all risk factors for pelvic prolapse, and can negatively affect a woman's quality of life [12].

Use of vaginal pessaries as an alternative non-surgical treatment for POP has been used for centuries [13]. It is the preferred method of treatment among many women. Despite pessaries being a minimally invasive, low-risk option, they can cause mild to morbidly serious complications, from discharge and odor to vaginal fibrosis and fistulas if proper care is not taken [14].

The incidence of neglected pessaries causing fistulas is rare [7], and there is limited data on long-term risk of complications for the use of pessaries [2]. Nonetheless, complications have been reported in the literature several times [4-8], 91\% of which the cause was negligence [6].

Location of the fistula varies with the shape and material the pessary is made of. Rectovaginal and vesicovaginal fistulas are more common with PVC and rubber pessaries. Further complications can result from fistulas, such as hydronephrosis, fecal impaction, and urosepsis [6].

Although cases of rectovaginal fistulas have been reported as a complication of a neglected pessaries, this is the first reported case of fistula perforating the small bowel. Moreover, it is the only reported case of pessary complication in SA.

Advancements in medical care, as well as increased awareness, have both contributed to reducing the incidence of such cases. Nonetheless, such complications may still occur, thus, practitioners need to be reminded of the importance of providing proper care to these patients. Therefore, we advise women with easily removable pessaries to remove and clean the pessary every two to three months, if possible, whereas a follow-up is recommended every six months for support pessaries to ensure there are no ulcerations, granulation tissue, or bruising. Foul-smelling discharge should raise concern and is important to mention to the physician.

\section{Competing Interests}

The authors declare that they have no competing interests.

\section{Author Contributions}

Al-Badr: contributions to conception, drafting the manuscript and final approval of the version to be published.

T. Al-Badr: contributions to conception, drafting the manuscript and final approval of the version to be published.

L. Al-Badr: contributions to conception, drafting the manuscript and final approval of the version to be published.

\section{References}

1. Handa VL, Jones M (2002) Do pessaries prevent the progression of pelvic organ prolapse? Int Urogynecol J Pelvic Floor Dysfunct 13: 349-351.

2. Fernando RJ, Thakar R, Sultan AH, Shah SM, et al. (2006) Effect of vaginal pessaries on symptoms associated with pelvic organ prolapse. Obst Gyn 108: 93-99.

3. Jones KA, Harmanli O (2010) Pessary use in pelvic organ prolapse and urinary incontinence. Rev Obstet Gynecol 3: 3-9.

4. Dangal G ( 2007) Forgotten vaginal pessary retrieved after forty-five years of insertion. Int J Gyn Obst 9.

5. Arias BE, Ridgeway B, Barber MD (2008) Complications of neglected vaginal pessaries: case presentation and literature review. Int Urogynecol J Pelvic Floor Dysfun 19: 1173-11788.

6. Abdulaziz M, Stothers L, Lazare D, Macnab A (2015) An integrative review and severity classification of complications related to pessary use in the treatment of female pelvic organ prolapse. Canadian Uro Ass J 9: E400E406.

7. Hanavadi S, Durham-Hall A, Oke T, Aston N (2004) Forgotten vaginal pessary eroding into rectum. Ann R Coll Surg Engl 86: W18-19.

8. Powers K, Grigorescu B, Lazarou G, Greston WM, Weber T (2008) Neglected pessary causing a rectovaginal fistula: a case report. J Reprod Med 53: 235-237.

9. Al-Badr A, Brasha H, Al-Raddadi R, Noorwali F, Ross S (2012) Prevalence of urinary incontinence among Saudi women. Int J Gyn Obstet 117: 160163.

10. Minassian VA, Drutz HP, Al-Badr A (2003) Urinary incontinence as a worldwide problem. Int J Gyn Obstet 82: 327-338.

11. Al-Badr AH, Kamil AG, Wahbah EF, Zimmerman VA, Al-Tannir MA (2010) Characteristics of women attending a urogynecology clinic in Riyadh. Saudi Med J 31: 86-87.

12. Siddiqui NY, Edenfield AL (2014) Clinical challenges in the management of vaginal prolapse. Int J Womens Health 6: 83-94.

13. Lamers B, Broekman B, Milani A (2011) Pessary treatment for pelvic organ prolapsed and health-related quality of life: a review. Int Urogyncol J 22 : 637-644.

14. Alperin M, Khan A, Dubina E, Tarnay C, Wu N, et al. (2013) Patterns of Pessary Care and Outcomes for Medicare Beneficiaries With Pelvic Organ Prolapse. Female Pelvic Med Recons Surg 19: 142-147.

15. Sarma S, Ying T, Moore K (2009) Long-term vaginal ring pessary use: discontinuation rates and adverse events. BJOG: An Int J Obst Gyn 116: 1715-1721. 